\title{
HHMI to support young physician-scientists
}

$T_{1}$

he Howard Hughes Medical Institute (HHMI) recently announced the recipients of its 2008 Early Career Physician-Scientist award, which provides support to young physician-scientists as they begin their independent careers.

This year's 19 recipients will each receive $\$ 375,000$ over five years. The one restriction on the prize is that the money must be used for direct research expenses, such as purchasing equipment or paying a technician's salary, and not the recipient's salary. The HHMI says it hopes that the award will give physician-scientists the time that they need to develop their research programs at a vulnerable point in their career, and to facilitate this further, they require that awardees devote at least $70 \%$ of their time to research (1).

"Many physician-scientists drop out of research during their first few years in the field, discouraged by failed grant applications or the lack of time to focus on their research," noted Peter J. Bruns, vice president for grants and special programs at the HHMI. "We want to encourage scientists who are doing important work turning basic research into treatments that will have a major impact on health" (1). It was with these goals in mind that the HHMI established the Early Career Physician-Scientist award in 2006, when 13 young physician-scientists were each given $\$ 150,000$ over three years, and then expanded the number, size, and duration of the awards

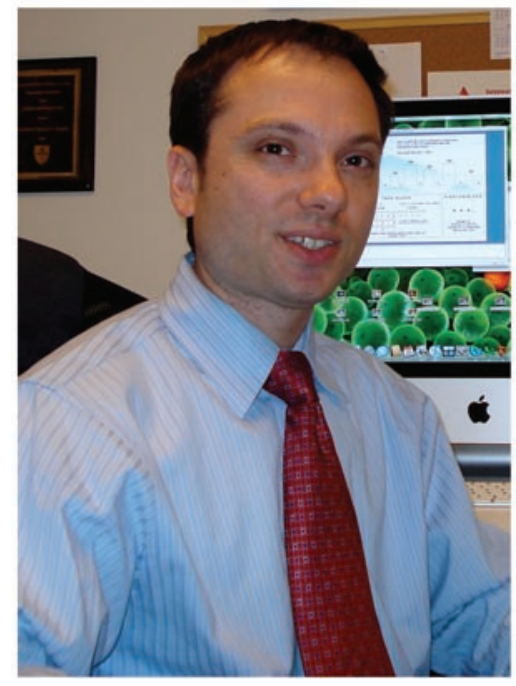

Joshua Roffman and Yvonne Chan, two of 19 young physician-scientists awarded the 2008 HHMI Early Career Physician-Scientist award.

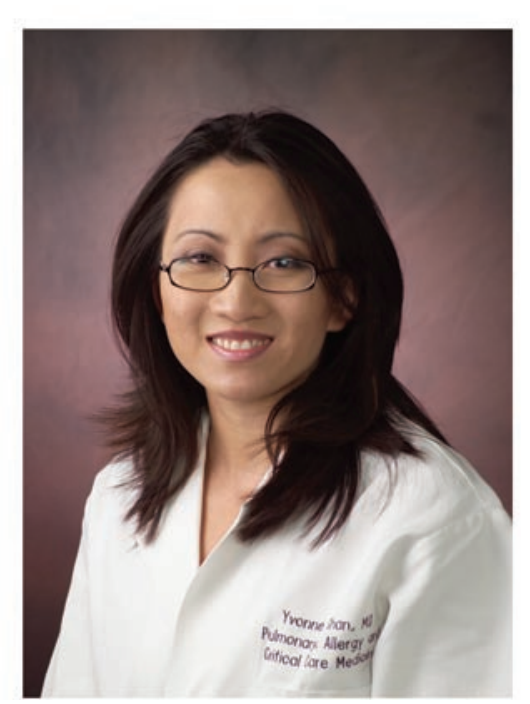

in 2007, when there were 20 awardees each given $\$ 375,000$ over five years.

To further strengthen the core aims of the award, it is only open to physicians who have already taken time off from medical school to undertake research through either the HHMI-NIH Research Scholars Program (which enables medical, dental, and veterinary students to spend a year conducting research at the NIH) or the HHMI Research Training Fellowships for Medical Students (which enable medical, dental, and veterinary students to spend a year conducting research at academic institutions other than the NIH). In addition, only individuals who have spent less than two years in a tenure-track position are eligible to apply for the award.

Applicants for the award can propose research projects in basic, translational, or applied biomedical science, and the projects to be undertaken by this year's recipients range from understanding the molecular mechanisms underlying insulin resistance, to identifying genetic signatures of different cancers, to understanding how HIV damages the nervous system.

Understanding the heritable defects associated with schizophrenia is the goal of Joshua Roffman, an MD at Harvard Medical School and Massachusetts General Hospital, Boston, who became interested in this aspect of research during his time as a neuroscience major at Amherst College, which he says opened his eyes to the many impor-

tant questions that remain unanswered in schizophrenia research. Roffman's year as an HHMI-NIH Research Scholar in Daniel Weinberger's laboratory, which gave him insight into the potential that translational neuroimaging holds for discerning some of the most complex aspects of schizophrenia, also proved important in shaping the research proposal honored with the HHMI Early Career Physician-Scientist award. Roffman told the JCI that this award was his first large grant and that he was very excited about the opportunity that it had given him at such an early stage in his career: "The award will give us the freedom to take a 'big picture' approach to understanding heritable deficits in schizophrenia.” Roffman further underlined the importance of the award to his prospects as a physician-scientist, saying, "There is no question that the award will enable me to answer translational research questions that would have been difficult to address through other funding mechanisms. In fact, this award makes it possible not only to survive as a physician-scientist but to thrive in a tough funding climate."

Another awardee, Yvonne Chan, an MD at the University of Pittsburgh School of Medicine, plans to use her award to investigate whether dysregulated immune responses play a role in the pathogenesis of bronchiectasis in cystic fibrosis (CF) by analyzing lung tissue from patients with CF who are undergoing lung transplant. Chan told the JCI that she had worried about the costly nature of maximally extracting data from each tissue sample and that before receiving the award she had contemplated dispensing with the project. Chan also added that she had felt vulnerable as a junior faculty member and that her attention to research might have been the most precarious of all her priorities - to be at the forefront of science and innovation as well as to be a competent clinician, an inspiring educator, and a good mother but that being a recipient of the HHMI Early Career Physician-Scientist award has given her the validation she needed to continue her career as a physician-scientist.

\section{Karen Honey}

1. Howard Hughes Medical Institute. 2008 June 05. Early career physician-scientists awarded $\$ 7.1$ million to pursue research. HHMI Institute News. http://www.hhmi.org/news/ 20080605earlycareerPS.html. 